when producing the cheap booklets for villagers in India?

M.F. Ingham: Although the captions to the pictures were written in English, the language of the text was very simple and could easily be translated into any other language or dialect.

\title{
TEACHING AND POPULARIZING ASTRONOMY IN EGYPT AND OTHER ARAB COUNTRIES
}

\section{A. Aiad}

Astronomy Department, Faculty of Science, Cairo University, Egypt

The recent astronomy of the Arab countries began by the last decade of the 19th century in Alger and the first decade of the 20th century in Helwan. Two Arab countries have been members of the IAU, namely Egypt (since 1925) and Iraq (since 1976). Saudi Arabia, Algeria, and Morocco became members in 1988. We restrict ourselves here to the teaching and popularizing of astronomy.

\section{Egypt}

In Egypt there is a single department of astronomy; since 1937 it has belonged to the Faculty of Science of Cairo University. A B.Sc. in astronomy requires two years' study of mathematics and physics followed by two more years devoted mainly to astronomy, including a small project. Elementary courses for other sciences, such as geography and geophysics, are also taught at Cairo University and the American University in Cairo.

Alazhar (Islamic) University has approved an astronomy department. The first staff candidate has recently been sent in a mission to University College London for his Ph.D.

Daily astronomical shows and specials shows for schools have been presented in the planetarium of Cairo since 1967.

The Astronomical Society of Egypt was founded in 1976 and has published a quarterly Arabic magazine, "World of Astronomy and Space," since 1983. A one or two-week school for 30-60 physics and mathematics teachers has been held annually by the society since 1983 . The teachers attend lectures, receive practical training, and visit the planetarium and observatory. They have been more interested in lectures illustrated with slides, video, and movies than with normal lectures. They were most impressed when they saw the heavenly bodies and stellar spectra through the telescope.

After each school the teachers become interested in astronomy, apply to be members of the society, and, of course, popularize astronomy more among their 
students. Some of them discover an interest and start to study astronomy. There is a one-year qualification program if they have their B.Sc. in physics or mathematics.

The result of such schools showed in the 1987/1988 academic year, when some short units on astronomical concepts were added to the physics curriculum of the secondary schools.

\section{Other Arab Countries}

The activities of the other Arab countries could be summarized as follows:

\subsection{Teaching of Astronomy}

In Ryadh and Jeddah, astronomy departments teach astronomy for all sciences. The university college of Bahrain, The Benighazi University (Libya), and some Iraqi universities are introducing astronomy for physics students.

\subsection{Popularization of Astronomy}

Kuwait has a planetarium and a science club with a nucleus of astronomy that publishes a quarterly Arabic magazine: "The Galaxy." Saudi Arabia, Jordan, Morocco, and Syria each has an astronomical society. Sudan has an astronomical club.

To sum up: The Arab area has about 50 astronomers (among about 150 million inhabitants), 3 departments, 2 planetariums, and 7 astronomical societies and clubs.

Generally each of those institutions works alone. They suffer from a deficiency of educational materials. Limited funds or memberships or both do not allow attractive programs or publishing of books and magazines.

In order to improve teaching and popularizing astronomy in the Arab area, one has to seek some sort of regional astronomical group that would sponsor meetings, cooperation in publishing books and magazines, exchange of educational materials, and cooperation with other organizations.

\section{Discussion}

S. Torres-Peimbert: It is of great interest that we find out about the astronomical situation in Arab countries. We think it would be particularly interesting to identify the universities where astronomy is being taught and perhaps establish programs with other universities to obtain information like periodicals and books. 